\title{
HUBUNGAN SOCIAL ENGAGEMENT DENGAN FUNGSI KOGNITIF PADA PASIEN PASCA STROKE DI RSUD. Dr. PIRNGADI KOTA MEDAN
}

\author{
Rinawati $^{1)}$, Elmeida Effendy ${ }^{2)}$, Sri Eka Wahyuni ${ }^{3)}$ \\ ${ }^{1}$ Sekolah Tinggi Ilmu Kesehatan Sumatera Utara \\ ${ }^{2}$ Psikiatri Fakultas Kedokteran, Universitas Sumatera Utara, Medan \\ ${ }^{1,3}$ Program Studi Magister Ilmu Keperawatan, Universitas Sumatera Utara, Medan \\ Email: rinawatitanjung1981@gmail.com
}

\begin{abstract}
Abstrak
Social engagement merupakan terpeliharanya hubungan sosial dalam aktivitas interaksi sosial pasien pasca stroke. Peranan social engagement berhubungan dengan fungsi kognitif pasien pasca stroke. Gangguan fungsi kognitif pasien pasca stroke diakibatkan adanya gangguan aliran darah otak (ADO) yang dapat menyebabkan suplai darah tidak adekuat sehingga menimbulkan gangguan fungsional otak. Dampak gangguan fungsi kognitif berpengaruh pada kondisi psikologis pasien. Tujuan penelitian ini adalah menguji hubungan social engagement dengan fungsi kognitif pada pasien pasca stroke.

Desain penelitian ini adalah korelasi. Jumlah sampel dalam penelitian ini adalah 47 pasien pasca stroke. Penelitian dilakukan di RSUD Dr. Pirngadi Medan. Pengambilan sampel dengan menggunakan teknik consecutive sampling. Pengumpulan data dengan menggunakan kuesioner, analisa data dengan menggunakan korelasi pearson.

Social engagement pada pasien pasca stroke berada pada kategori baik (55.3\%). Kebanyakan dari responden mempunyai fungsi kognitif pada kategori tidak ada gangguan (42.6\%). Hubungan social engagement dengan fungsi kognitif menunjukkan bahwa ada hubungan yang signifikan $(r=0.509, p=0.000)$. Penelitian ini menunjukkan ada hubungan social engagement dengan fungsi kognitif. Hasil penelitian ini merekomendasikan kepada perawat dapat meningkatkan kualitas hidup pasien pasca stroke dengan meningkatkan social engagement.
\end{abstract}

Kata kunci: Social engagement, Pasca stroke, Fungsi kognitif

\begin{abstract}
Social engagement is the maintenance of social relations in the activities of social interaction of patients after stroke. The role of social engagement is related to the cognitive function of post-stroke patients. Impaired cognitive function of post-stroke patients is caused by a disruption of cerebral blood flow $(A D O)$ which can cause an inadequate blood supply which causes functional brain disorders. The impact of impaired cognitive function affects the psychological condition of the patient. The purpose of this study was to examine the relationship of social engagement with cognitive function in post-stroke patients.

The design of this study is correlation. The number of samples in this study were 47 patients post-stroke. The study was conducted at Dr. Pirngadi Medan. Sampling using consecutive sampling technique. Data collection using a questionnaire, data analysis using Pearson correlation.

Social engagement in post-stroke patients was in the good category (55.3\%). Most of the respondents had cognitive function in the category of no interference (42.6\%). The relationship of social engagement with cognitive function showed that there was a significant relationship $(r=0.509, p=0.000)$. This study shows that there is a relationship of social engagement with cognitive function. The results of this study recommend that
\end{abstract}


nurses can improve the quality of life of post-stroke patients by increasing social engagement.

Keywords: Social engagement, Post-stroke, Cognitive function

\section{PENDAHULUAN}

Stroke dikenal dengan Gangguan Peredaran Darah Otak (GPDO) merupakan suatu sindrom yang disebabkan adanya gangguan aliran darah pada salah satu bagian otak yang menimbulkan gangguan fungsional otak berupa defisit neurologik sehingga mengakibatkan seseorang menderita kelumpuhan dan kematian (Dinata, 2012). World Health Organization (WHO) menetapkan bahwa stroke merupakan suatu sindrom klinis yang ditandai dengan gejala berupa gangguan fungsi otak secara fokal atau global yang dapat menimbulkan kematian atau kelainan yang menetap lebih dari 24 jam, tanpa penyebab lain kecuali gangguan vaskuler (Ovina, 2012).

Stroke menyebabkan berbagai defisit neurologik, tergantung pada lokasi lesi (pembuluh darah mana yang tersumbat), ukuran, area yang perfusinya tidak adekuat, dan jumlah aliran darah kontra lateral (sekunder atau aksesori) (Ignatavicius, 2013). Stroke dapat berdampak pada berbagai fungsi tubuh. Dampak stroke secara klinis diantaranya adalah kehilangan motorik, kehilangan komunikasi, gangguan persepsi, kerusakan fungsi kognitif dan efek psikologik dan disfungsi kandung kemih (Lewis, 2014).

Data studi epidemiologi stroke di Indonesia secara komprehensif dan akurat belum ada, dengan meningkatnya harapan hidup tendensi peningkatan kasus stroke akan meningkat dimasa yang akan datang. Menurut WHO, Indonesia telah menempati peringkat ke-97 dunia dengan jumlah angka kematian mencapai 138.268 orang $(9,70 \%)$ dari total kematian yang terjadi pada tahun 2011 (Suryantika, 2013). Kementrian Kesehatan RI (2013), bahwa jumlah penderita stroke di Indonesia berdasarkan diagnosa tenaga kesehatan sebanyak 1.236 .825 orang (7\%). Berdasarkan Riskesdas (2013) bahwa 7 dari 1000 orang di Indonesia terserang stroke. Stroke telah menempati peringkat ke-2 di daerah Sumatera Utara yaitu sebanyak 92.078 orang $(10,3 \%)$.

Prevalensi penderita stroke di seluruh dunia terus meningkat pada usia dibawah 45 tahun dengan perkiraan yaitu 7-15 kasus/100.000 penduduk/tahun dan pada kelompok anak-anak, yaitu 1-8 kasus/100.000/tahun (Birawa \& Amalia, 2015). Pada konferensi ahli saraf internasional di Inggris dilaporkan bahwa terdapat lebih dari 1000 penderita stroke berusia kurang dari 30 tahun (American Heart Association, 2010).

Hasil penelitian Wardhani (2013) tentang prevalensi gangguan fungsi kognitif dan depresi pada pasien stroke didapatkan bahwa yang mengalami gangguan fungsi kognitif $67,5 \%$ dimana gangguan ringan $27 \%$, gangguan sedang $40,5 \%$ dan gangguan berat tidak ada.

Faktor-faktor resiko gangguan fungsi kognitif berasal dari genetik, usia, penyakit, dan tempat tinggal (Patterson, 2008). Selain itu faktor lingkungan juga beresiko menyebabkan gangguan fungsi kognitif, seperti hubungan atau keterlibatan sosial (social engagement). Social engagement dapat diartikan dalam banyak dimensi (Cohen \& Wills, 1985). Social Engagement dapat didefinisikan sebagai interaksi sosial dengan lainnya dan pendekatan pada individual dan aktivitas sosial dengan fasilitas (Mor et al., 1995). Menurut Bassuk, Glass, \& Berkman (1999), bahwa Social Engagement merupakan kemampuan memelihara hubungan sosial.

Penelitian Rosita (2012) menunjukan bahwa interaksi sosial berhubungan 
dengan fungsi kognitif. Penelitian Wreksoatmodjo (2012) menunjukan bahwa social engagement mempengaruhi fungsi kognitif. Penelitian-penelitian umumnya menunjukan bahwa social engagement mempengaruhi fungsi kognitif. Mengingat social engagement terdiri komponen jaringan sosial yaitu kemampuan memelihara luasnya hubungan sosial dan aktivitas sosial yaitu tingkat partisipasi dalam kegiatan di masyarakat, maka perlu dilakukan penelitian lebih lanjut (Bassuk, Glass, Berkman, 1999).

Hubungan antara social engagement dengan fungsi kognitif mencerminkan faktor gaya hidup lainnya belum diteliti secara luas. Selain itu, pengetahuan tentang dasar dari asosiasi ini masih terbatas. Salah satu alasan untuk ketidakpastian ini adalah bahwa kedua komponen social engagement dan fungsi kognitif merupakan konstruksi multi dimensi namun sering dinilai dengan ukuran dimensional singkat.

Pengukuran social engagement untuk tingkat fungsi kognitif pada pasien stroke menggunakan tiga ukuran keterlibatan sosial yaitu ukuran jaringan sosial, frekuensi partisipasi dalam kegiatan sosial dan tingkat persepsi dukungan sosial (Wilson, 2002). Mengingat Indonesia mempunyai pola hubungan keluarga yang mungkin berbeda dengan yang ada di negara lain, perlu diketahui apakah keterlibatan sosial (social engagement) berpengaruh terhadap fungsi kognitif penderita stroke).

\section{METODE}

Desain penelitian yang digunakan yaitu kuantitatif. Penelitian ini menggunakan korelasi untuk mengidentifikasi hubungan social engagement dengan fungsi kognitif pasien pasca stroke di RSUD Dr. Pirngadi Medan. Metode sampling menggunakan teknik consecutive sampling, sebanyak 47 sampel. Instrumen pengumpulan data dalam penelitian ini berupa instrument yang berhubungan dengan karakteristik responden, social engagement dan fungsi kognitif. Analisis data pada penelitian ini menggunakan Product-Moment Correlation Coefficient (Pearson's $r$ ).

\section{HASIL}

Social engagement pada pasien pasca stroke ditunjukkan pada Tabel 1 Social engagement pada responden terutama berada pada kategori baik (55.3\%).

Tabel 1. Social Engagement pada Pasien Pasca Stroke Tahun 2017 (N=47)

\begin{tabular}{|c|c|c|}
\hline \multirow[t]{2}{*}{ Kategori } & \multicolumn{2}{|c|}{ Total } \\
\hline & $\mathrm{f}$ & $\%$ \\
\hline Baik & 26 & 55,3 \\
\hline Buruk & 21 & 44,7 \\
\hline
\end{tabular}

Tabel 2. Fungsi Kognitif pada Pasien Pasca Stroke Tahun 2017 (N=47)

\begin{tabular}{|c|c|c|}
\hline \multirow[t]{2}{*}{ Kategori } & Total & \\
\hline & $\mathrm{f}$ & $\%$ \\
\hline Tidak & 20 & 42,6 \\
\hline Gangguan & 18 & 38,3 \\
\hline Gangguan & 9 & 19.1 \\
\hline Ringan & & \\
\hline Gangguan Berat & & \\
\hline
\end{tabular}

kognitif pada pasien pasca stroke ditunjukkan pada Tabel 2. Mayoritas dari responden mempunyai fungsi kognitif pada kategori tidak ada gangguan dan gangguan ringan $(42.6 \%)$. 
Tabel 3. Silang Antar Social Engagement dengan Fungsi Kognitif pada Pasien Pasca Stroke Tahun $2017(\mathrm{~N}=47)$

\begin{tabular}{|c|c|c|c|c|c|c|c|c|c|}
\hline \multirow[t]{3}{*}{ No } & \multirow{3}{*}{$\begin{array}{l}\text { Social } \\
\text { Engagement }\end{array}$} & \multicolumn{6}{|c|}{ Fungsi Kognitif } & \multirow{2}{*}{\multicolumn{2}{|c|}{ Total }} \\
\hline & & \multicolumn{2}{|c|}{$\begin{array}{l}\text { Tidak Ada } \\
\text { Gangguan }\end{array}$} & \multicolumn{2}{|c|}{$\begin{array}{c}\text { Gangguan } \\
\text { Ringan }\end{array}$} & \multicolumn{2}{|c|}{$\begin{array}{c}\text { Gangguan } \\
\text { Berat }\end{array}$} & & \\
\hline & & $\mathbf{f}$ & $\%$ & $\mathbf{f}$ & $\%$ & $\mathbf{f}$ & $\%$ & $\mathbf{f}$ & $\%$ \\
\hline 1 & Baik & 15 & 57,7 & 11 & 42,3 & 0 & 0,0 & 26 & 100 \\
\hline \multirow[t]{2}{*}{2} & Buruk & 5 & 23,8 & 7 & 33,3 & 9 & 42,9 & 21 & 100 \\
\hline & Total & 20 & 42,6 & 18 & 38,3 & 9 & 19,1 & 47 & 100 \\
\hline
\end{tabular}

Tabel silang antar social engagement dengan fungsi kognitif pada pasien pasca stroke ditunjukkan pada Tabel 3. Dari 26 orang dengan social engagement terdapat tidak ada gangguan fungsi kognitif sebanyak 15 orang $(57,7 \%)$ dan dari 21 orang dengan social engagement buruk terdapat gangguan berat fungsi kognitif sebanyak 9 orang $(42,9 \%)$.

Tabel 4. Hubungan Social Engagement dengan Fungsi Kognitif pada Pasien Pasca Stroke Tahun $2017(\mathrm{~N}=47)$

\begin{tabular}{lcc}
\hline Variabel & $\mathbf{r}$ & $\boldsymbol{p}$-value \\
\hline Social Engagement-Fungsi Kognitif & 0,509 & 0,000
\end{tabular}

Uji Korelasi Pearson

Ada hubungan yang positif antara social engagement dengan fungsi kognitif, dimana signifikan secara statistik $(\mathrm{r}=0,509, \mathrm{n}=47$ dan $\mathrm{p}=0,000)$.

\section{PEMBAHASAN}

Hubungan social engagement dengan fungsi kognitif, menggunakan uji korelasi pearson menunjukkan bahwa ada hubungan yang signifikan adalah nilai $r=0.509 \quad(p=0.000) \quad$ (Tabel 4). Berdasarkan penelitian sebelumnya yang dilakukan oleh Wreksoatmodjo (2014) menyebutkan bahwa sebanyak 56.9\% (58 orang) lanjut usia dengan social engagement buruk memiliki fungsi kognitif buruk. Sedangkan di antara lanjut usia dengan social engagement baik sebanyak $27.2 \% \quad$ (50 orang) memiliki fungsi kognitif buruk. Uji statistik menggunakan analisis Cox Regression menunjukkan ada hubungan bermakna antara social engagement dengan fungsi kognitif (nilai $\mathrm{p}<0.0001$ ). Lanjut usia dengan social engagement buruk memiliki risiko 2.093 (1.5652.799) kali lebih besar untuk mempunyai fungsi kognitif buruk dibandingkan lanjut usia dengan social engagement baik.

Social engagement adalah interaksi sosial dengan lainnya dan pendekatan pada individual dan aktvitas sosial (Mor et al., 1995). Peranan social engagement diduga mempengaruhi fungsi kognitif (Barnes, 2007). Penelitian Rosita (2012) menunjukan bahwa interaksi sosial berhubungan dengan fungsi kognitif yaitu hasil uji Chi Square diperoleh $X^{2}=6,830$ dan $p=0,00$. Penelitian Wreksoatmodjo (2012) di Jakarta menunjukan bahwa hasil uji statistik menggunakan analisis Cox Regression diperoleh nilai $p<0.00$. Penelitian-penelitian umumnya menunjukan bahwa social engagement mempengaruhi fungsi kognitif. Mengingat social engagement terdiri komponen jaringan sosial yaitu kemampuan memelihara luasnya hubungan sosial dan aktivitas sosial yaitu tingkat partisipasi dalam kegiatan di masyarakat (Bassuk, Glass, Berkman, 1999). 
Tingkat partisipasi dalam kegiatan di masyarakat dikenal dengan dukungan sosial (social support). Sejalan dengan Uchino (2004, dalam Sarafino \& Smith, 2012) menyatakan bahwa social support atau dukungan sosial mengacu pada kenyamanan, kepedulian, atau bantuan yang diterima oleh individu dari seseorang atau sekelompok orang. Dukungan sosial bisa didapat dari banyak sumber seperti keluarga, pasangan, dokter, atau orang-orang dalam organisasi dan komunitas (Sarafino \& Smith, 2012).

Menurut Olson, Breckler, \& Wiggins (2006) dukungan sosial adalah bantuan yang diberikan adalah orang-orang yang berada dalam lingkungan sosial individu seperti keluarga, teman, dan masyarakat. Dukungan sosial juga bisa diartikan sebagai pemberian perasaan nyaman, baik secara fisik maupun psikologis keluarga kepada seseorang untuk menghadapi masalah (Baron \& Byrne, 1997). Beberapa teori yang mengemukakan bahwa dukungan sosial merupakan suatu bentuk ungkapan emosional yang berfungsi melindungi seseorang dari kecemasan yang ditimbulkan. Dukungan sosial mampu memberikan suatu bentuk informasi atau nasehat pada seseorang yang diberikan berdasarkan keakraban sosial atau karena kehadiran seseorang mempunyai manfaat emosional oleh efek keputusan yang sesuai dengan keinginan nantinya.

Keakraban memungkinkan seseorang memperoleh kerekatan emosional, sehingga menimbulkan rasa aman bagi yang menerima. Orang yang menerima merasa tentram, aman dan damai yang yang ditunjukan dengan sikap tenang dan bahagia. Sumber ini paling sering diperoleh dari pasangan hidup, anggota keluarga, teman dekat, sanak saudara yang akrab yang memiliki hubungan yang harmonis.
Pemeliharaan hubungan dinilai dari kuantitas atau jaringan sosial dan kualitas yaitu aktivitas sosial. Dalam hal ini sangat diperlukan peningkatkan kualitas keterlibatan keluarga atau dukungan keluarga. Dukungan keluarga merupakan segala bentuk perilaku dan sikap positif yang diberikan keluarga kepada salah satu anggota keluarga yang sakit yaitu anggota keluarga yang mengalami masalah kesehatan (Friedman, 2010).

Peneliti mengasumsikan bahwa social engagement sangat berperanan penting pada pasien pasca stroke. Mengingat kondisi pasien yang mengalami gangguan fungsi kognitif akibat dampak dari serangan stroke maka perlu dilakukan peningkatan keterlibatan lingkungan seperti pasangan hidup, anggota keluarga, sanak saudara, teman dekat untuk pemeliharaan dukungan sosial dalam aktivitas interaksi sosial pasien pasca stroke. Dengan hal ini pasien pasca stroke merasa aman, tentram dan damai bahkan bisa menjadi lebih tenang dan bahagia.

\section{KESIMPULAN}

Hasil penelitian ini menunjukkan bahwa ada hubungan social engagement dengan fungsi kognitif. Direkomendasikan kepada perawat agar dapat meningkatkan kualitas hidup pasien pasca stroke dengan meningkatkan social engagement.

\section{REFERENSI}

1. American Heart Association. (2010). Heart disease \& stroke statistics 2010 Update. Dallar, Texas: American Heart Association.

2. Barnes, L. L., Mendes de Leon, C.F, Wilson, R.S., Bienias, J.L., \& Evans, D.A. (2007). Social resources and cognitive decline in a population of older african americans and whites. Journal of national institutes of health. 28, 63(12). 2322-6.

3. Bassuk, S. S., Glass, T.A., \& Berkman, L.F. (1999). Social disengagement and incident cognitive 
decline in community-dwelling elderly persons. Ann Intern Med.

4. Birawa, A. B. P., \& Amalia, L. (2015). Stroke pada usia muda. Staf bagian neurologi Fakultas Kedokteran Universitas Padjadjaran, Bandung. Vol. 42, 10.

5. Breckler, S. J., Olson, J., \& Wiggins, E. (2006). Social psychology alive. Boston: Thomson Wadsworth.

6. Cohen, S., \& Wills, T.A. (1985). Stress, social support, and the buffering hypothesis. Pittsburgh : Department Of Psychology Carnegie Mellon University. 98:310-57, 1985.

7. Dinata, C.A., Safrita, Y., \& Sastri, S. (2012). Gambaran Faktor Risiko dan Tipe Stroke pada Pasien Rawat Inap di Bagian Penyakit Dalam RSUD Kabupaten Solok Selatan Periode 1 Januari 2010 -31 Juni 2012. Jurnal Kesehatan Andalas. Padang : FKUNAND.

8. Ignatavicius, D. D., \& Workman, M. L. (2013). Medical - surgical nursing: clients - centered collaborative care. Edisi 9. Missouri: Saunders Elsevier.

9. Kemenkes RI. (2013). Riset Kesehatan Dasar; RISKESDAS. Jakarta: Balitbang Kemenkes RI Dermawan D dan Rusdi.

10.Lewis, 1. \& Sharon. (2014). Medical surgical nursing: assessment and management of clinical problem. Elsevier.

11.Mor, et, al. (1995). The Structureof Social Engagement Among Nursing Home Residents. Journal of Gerontology: Psychological Sciences 1995.Vol.50B.No.I.PI-P

12.Ovina, Yulia. Riowastu, Idtrat \& Yuwono. (2012). Hubungan Pola Makan, Olah Raga dan Merokok Terhadap Prevalensi Penyakit Stroke Non Hemoragik di RSUD Jambi. Jurnal Universitas Jambi.
13.Patterson, C., Feightner, J.W., Garcia, A., Hsiung, G. Y. R., MacKnight, C. \& Sadovnick, A. D. (2008). Diagnosis and treatment of dementia: Risk assessment and primary prevention of Alzheimer disease. CMAJ, 178(5):548-56.

14.Rosita Dewi. 2012. Hubungan Antara Fungsi Kognitif dengan Kemampuan Interaksi Sosial Pada Lansia di Kelurahan Mandan Wilayah Kerja Puskesmas Sukoharjo. Thesis, Universitas Muhammadiyah Surakarta.

15.Sarafino, E.P., \& Smith, T.W. (2012). Health Psychology: Biopsychosocial Interactions. John Wiley \& Sons Inc.

16.Suryantika, F. (2013). Gambaran Fungsi Kognitif Pada Pasien Stroke Post Opname Di Poliklinik. diakses tanggal 19 Oktober 2013, dari http://www.academia.edu/409208.

Wardhani, I. (2013). Prevalensi Gangguan Fungsi Kognitif Dan Depresi Pada Pasien Stroke Di Irina F Blu Rsup Prof. Dr. R. D. Skripsi: Fakultas Kedokteran Universitas Sam Ratulangi Manado.Waxman, S.G. (2007). The limbic system. In : Lange Neuroanatomy. New york: the macgraw-hill companies. p. 28-30.

17.Wilson, R.S., Bennett, D.A., Bienias, J,L., Aggarwal, N.T., Mendes De Leon, C.F., Morris, M.C., Schneider, J.A., \& Evans, D.A. (2002) .Cognitive activity and incident $A D$ in a population-based sample of older persons. Neurology, 59(12):1910-4.

18.Wreksoatmodjo., \& Riyanto, B. (2012). Hubungan Social Engangement Dengan Fungsi Kognitif. Jakarta. CDK-190 39 (2).

19.Wreksoatmodjo., \& Riyanto, B. (2014). Pengaruh Social Engangement Dengan Fungsi Kognitif Lanjut Usia. Jakarta. CDK-214 41 (3). 